\title{
Cardiorespiratory effects of project energize: a whole-of region primary school nutrition and physical activity programme in New Zealand in 2011 and 2015
}

\author{
Carolyn Cairncross ${ }^{1}$, Victor Obolonkin ${ }^{1}$, Tara Coppinger ${ }^{2^{*}}$ (i) and Elaine Rush ${ }^{1}$
}

\begin{abstract}
Background: Since 2004, Sport Waikato has delivered Project Energize, a through-school nutrition and physical activity program to primary schools in the Waikato. As part of the program's continued assessment and quality control, the programme was evaluated in 2011 and 2015. This paper's aim was to compare the cardiorespiratory fitness (time to run $550 \mathrm{~m}\left(T_{550}\right)$ ) levels of children participating in Project Energize in 2011 and 2015.

Methods: In the 2011 evaluation of Project Energize, gender specific- $T_{550}$-for-age $Z$ scores $\left(T_{550} A Z\right)$ were derived from the $T_{550}$ of 4832 Waikato children (2527 girls; 2305 boys; 36\% Māori) aged between 6 and 12 years. In 2015, $T_{550}$ was measured for 4798 (2361 girls; 2437 boys; 32\% Māori) children, representative of age, gender and school socioeconomic status (SES). The $T_{550} \mathrm{AZ}$ for every child in the 2015 study and 2011 evaluation were derived and differences in $T_{550}$ between 2015 and 2011 by gender, SES and age were determined using independent t-tests. Multiple regression analysis predicted T550 Z score and run time, using year of measurement, gender, ethnicity, age and school SES.

Results: With and without adjustment, children in 2015 ran 550 m faster than in 2011 (adjusted Z score 0.06, time 11 s). Specifically, girls ran at a similar speed in 2015 as 2011 but boys were faster than in 2011 (Z score comparison $P<0.001$, mean difference $0.1895 \% \mathrm{Cl} 0.12,0.25$ ). Regression analysis showed time taken to run $550 \mathrm{~m}$ was $11 \mathrm{~s}$ less in 2015 compared with 2011. Boys ran it $13 \mathrm{~s}$ faster than girls (Z score 0.07) and for each 1 year age increase, children were $8 \mathrm{~s}$ slower (Z score 0.006 ). For each $10 \%$ decrease in SES, children were $3 \mathrm{~s}$ slower (Z score 0.004$)$ and Māori children were $5 \mathrm{~s}$ slower than Non-Māori children (Z score 0.15 ).

Conclusions: The findings from this study support the continuation of the delivery of Project Energize in the Waikato region of New Zealand, as cardiorespiratory fitness scores in 2015, compared to 2011, were improved, particularly for lower SES schools and for Māori children. Ethnically diverse populations, schools with higher deprivation and girls, continue to warrant further attention to help achieve equity.
\end{abstract}

Keywords: Cardiorespiratory fitness, Nutrition, Physical activity, Intervention

\footnotetext{
* Correspondence: tara.coppinger@cit.ie

${ }^{2}$ Department of Sport, Leisure \& Childhood Studies, Cork Institute of Technology, Cork, Ireland

Full list of author information is available at the end of the article
}

C C The Author(s). 2020 Open Access This article is licensed under a Creative Commons Attribution 4.0 International License, which permits use, sharing, adaptation, distribution and reproduction in any medium or format, as long as you give appropriate credit to the original author(s) and the source, provide a link to the Creative Commons licence, and indicate if changes were made. The images or other third party material in this article are included in the article's Creative Commons licence, unless indicated otherwise in a credit line to the material. If material is not included in the article's Creative Commons licence and your intended use is not permitted by statutory regulation or exceeds the permitted use, you will need to obtain permission directly from the copyright holder. To view a copy of this licence, visit http://creativecommons.org/licenses/by/4.0/ The Creative Commons Public Domain Dedication waiver (http://creativecommons.org/publicdomain/zero/1.0/) applies to the data made available in this article, unless otherwise stated in a credit line to the data. 


\section{Background}

The prevalence of obesity, a form of malnutrition, is high (10\%) in New Zealand children aged 2-14y [1]. Indigenous Māori children and those living in the most deprived areas are most at risk of obesity (16 and 20\%, respectively) [1]. Since 2005, in response to the need for prevention strategies in childhood settings, [2] Sport Waikato, funded by the Waikato District Health Board, has delivered Project Energize (PE), a through-primary school nutrition and physical activity programme [3]. This is the first intervention of its kind to be delivered to primary school children in New Zealand. It began initially as a cluster randomised controlled trial in 124 schools in 2005 [4]. Briefly, an 'Energizer'; a trained physical activity and nutrition change-agent works throughout the school year with lead teachers in 8 to 12 schools to achieve goals to provide healthier eating and quality physical activity opportunities. Example activities include the provision of professional development for teachers to teach fundamental movement skills [5], and the adaptation of the school environment to supply healthier foods and sports equipment upgrades. Since 2009, the intervention has reached all 252 primary schools in the Waikato region of New Zealand and its dose and specific components are tailored to each individual school [6]. The program's fidelity is monitored by the funder with quarterly reports of activities of Energizers and schools submitted to the Waikato District Health Board.

Due to the requirement for healthcare evaluations to conform to the randomised controlled trial model [7], the translation of research findings is difficult as cost and time constraints are common given the complex settings of schools $[8,9]$. Accountability both to children and funders (taxpayers) is required [10]. Frequently, changes in body mass index (BMI) alone have been used as the basis of such evaluations [11], however, an indicator of cardiorespiratory fitness, such as speed of running is also a marker of child health, [12] (particularly metabolic health), growth and development [13] and quality and quantity of physical activity [14, 15]. Given that evidence of effectiveness is poor in interventions incorporating physical activity, [16] an opportunity exists to utilise cardiorespiratory fitness data as a tool to effectively monitor and evaluate public-health interventions aimed at children.

A number of tests to measure physical fitness in school children have been developed, ranging from complex test batteries to simple run protocols [17]. The time taken to run $550 \mathrm{~m}\left(\mathrm{~T}_{550}\right)$ has been validated as a measure of cardiorespiratory fitness [18]. In the 2011 evaluation of Project Energize (14), the BMI, waist-to-height ratio and percentage body fat of Waikato schoolchildren were positively associated with an increase in T550, and participating children ran faster than children from Canterbury in New Zealand [19]. As a result, it was proposed that $\mathrm{T}_{550}$ would be, in 2015 , an alternative, pragmatic way to evaluate the effectiveness of Project Energize. This approach helped enable schools that were geographically remote, in areas of high deprivation and had ethnically diverse populations to participate in the evaluation [20].

Subsequently, the aim of this analysis was to compare cardiorespiratory fitness $\left(\mathrm{T}_{550}\right)$ times of Waikato children in 2015 with children measured in the first large scale evaluation of the programme in 2011 [19]. These follow-up measures were undertaken in 2015 to assess maintenance of the programme, which had been delivered continuously in all schools for at least 6 years. As a result, it was hypothesised that the run times in 2015, relative to age and gender, would be maintained or faster than 2011.

\section{Methods}

This retrospective study utilised two cross-sectional data sets of Waikato primary school children aged between 6 and 12 years. In 2011, 4832 children (2527 girls; 2305 boys; 36\% Māori) from 193 (out of a total of 232) schools and in 2015, 4798 (2361 girls; 2437 boys; 32\% Māori) children from 240 (out of 245) schools had time to run $550 \mathrm{~m}$ measured. The students in 2011 were not matched for students in 2015. However, this allowed for no child to be excluded; increasing participant numbers for analysis. For the 2011 measures, the Northern Y Regional Ethics Committee (NTY/10/04/41) provided ethical approval in 2010 and caregivers and children provided written and signed informed consent. In 2015, run times were measured in schools as part of a milestone report of effectiveness for the funder of PE (Waikato District Health Board). Anonymised run times and demographic information of gender, age in years and ethnicity, as recorded by schools as Māori or non-Māori, were provided for each child for the analysis. There were no inclusion/exclusion criteria for participation and all schools and children were invited to participate. The Auckland University of Technology ethics committee (AUTEC) provided written attestation that the analysis met ethical criteria. Socioeconomic status (SES) of each school was determined by the Ministry of Education on a scale of 1 to 10 , with decile 1 schools located in the lowest, and decile 10 schools in the highest SES areas [21].

The standardised protocol for $\mathrm{T}_{550}$ was followed [22] . In brief, after a standardised warm up, time taken for children to run five times around an outdoor, grassy, $110 \mathrm{~m}$ oval course $(26.5 \mathrm{~m}$ by $42.5 \mathrm{~m})$ was recorded $( \pm 1$ s). A maximum of 4-5 children ran together in groups according to their age (school year) and self-identified 
Table 1 Z score differences in time to run 550 m ( $\left.T_{550}\right)$ of Waikato primary school children in 2015 and 2011

\begin{tabular}{|c|c|c|c|c|c|c|}
\hline \multirow[t]{2}{*}{ Characteristic } & \multicolumn{2}{|c|}{$2015(n=4798)$} & \multicolumn{2}{|c|}{$2011(n=4832)$} & \multicolumn{2}{|c|}{ Difference Z score (2011 minus 2015) } \\
\hline & $\bar{n}$ & $\begin{array}{l}\mathrm{T}_{550} \mathrm{AZ} \\
\text { mean (SD) }\end{array}$ & $\bar{n}$ & $\begin{array}{l}T_{550} A Z \\
\text { mean (SD) }\end{array}$ & $\bar{P}$ & Difference $(95 \% \mathrm{Cl})^{\mathrm{a}}$ \\
\hline$\overline{\text { All }}$ & 4798 & $-0.11(1.236)$ & & $0.00(1.00)$ & $<0.001$ & $0.11(-0.15,-0.06)$ \\
\hline \multicolumn{7}{|l|}{ Gender } \\
\hline Boys & 2437 & $-0.18(1.26)$ & 2305 & $0.00(1.00)$ & $<0.001$ & $0.18(0.12,0.25)$ \\
\hline Girls & 2361 & $-0.04(1.21)$ & 2527 & $0.00(1.00)$ & 0.14 & $0.04(-0.02,0.10)$ \\
\hline \multicolumn{7}{|l|}{ Age } \\
\hline 6 years & 432 & $-0.10(1.48)$ & 358 & $0.09(0.98)$ & 0.037 & $0.19(0.01,0.37)$ \\
\hline 7 years & 1118 & $-0.09(1.29)$ & 1683 & $-0.05(1.00)$ & 0.36 & $0.04(-0.05,0.13)$ \\
\hline 8 years & 978 & $-0.11(1.24)$ & 539 & $0.07(1.04)$ & 0.005 & $0.18(0.06,0.30)$ \\
\hline 9 years & 973 & $-0.21(1.14)$ & 582 & $0.08(1.02)$ & $<0.001$ & $0.29(0.18,0.40)$ \\
\hline 10 years & 1297 & $-0.05(1.16)$ & 1670 & $-0.03(0.98)$ & 0.13 & $0.02(-0.06,0.10)$ \\
\hline \multicolumn{7}{|l|}{ Ethnicity } \\
\hline All Māori & 1516 & $0.16(1.25)$ & 1905 & $0.24(0.98)$ & 0.036 & $0.08(0.01,0.15)$ \\
\hline All Non-Māori & 3282 & $-0.24(1.21)$ & 2927 & $-0.16(0.98)$ & 0.005 & $0.08(0.02,0.14)$ \\
\hline Māori boys & 801 & $0.13(1.25)$ & 908 & $0.27(0.96)$ & 0.001 & $0.14(0.03,0.25)$ \\
\hline Māori girls & 715 & $0.20(1.25)$ & 997 & $0.21(1.02)$ & 0.85 & $0.01(-0.98,0.12)$ \\
\hline Non-Māori boys & 1636 & $-0.32(1.25)$ & 1397 & $-0.18(0.99)$ & $<0.001$ & $0.14(0.06,0.22)$ \\
\hline Non-Māori girls & 1646 & $-0.14(1.18)$ & 1530 & $-0.14(0.96)$ & 1.00 & $0.00(-0.07,0.07)$ \\
\hline \multicolumn{7}{|l|}{ SES } \\
\hline Decile $1^{\mathrm{b}}$ & 439 & $0.71(1.12)$ & 450 & $0.47(0.93)$ & 0.002 & $-0.24(-0.38,-0.11)$ \\
\hline Decile 2 & 435 & $0.59(1.15)$ & 615 & $0.31(0.99)$ & 0.006 & $-0.28(-0.41,-0.15)$ \\
\hline Decile 3 & 629 & $0.06(1.17)$ & 654 & $0.16(0.97)$ & 0.095 & $0.10(-0.02,0.22)$ \\
\hline Decile 4 & 306 & $-0.25(1.12)$ & 745 & $0.05(0.96)$ & 0.002 & $0.30(0.17,0.44)$ \\
\hline Decile 5 & 716 & $-0.23(1.27)$ & 397 & $-0.10(0.96)$ & 0.076 & $0.13(-0.01,0.27)$ \\
\hline Decile 6 & 501 & $-0.29(1.15)$ & 479 & $-0.04(0.94)$ & $<0.001$ & $0.25(0.12,0.38)$ \\
\hline Decile 7 & 475 & $-0.35(1.17)$ & 346 & $-0.16(0.94)$ & 0.013 & $0.19(0.04,0.34)$ \\
\hline Decile 8 & 611 & $-0.45(1.21)$ & 404 & $-0.32(0.93)$ & 0.067 & $0.13(-0.01 \cdot 0.27)$ \\
\hline Decile 9 & 352 & $-0.43(1.13)$ & 319 & $-0.25(0.99)$ & 0.029 & $0.18(0.02,0.34)$ \\
\hline Decile 10 & 334 & $-0.48(1.11)$ & 423 & $-0.53(0.97)$ & 0.51 & $-0.05(-0.20,0.09)$ \\
\hline
\end{tabular}

$\mathrm{T}_{550}$ time to run $550 \mathrm{~m}, \mathrm{~T}_{550} \mathrm{AZ}$ gender specific for-age z-scores

SD standard deviation

${ }^{a}$ Independent t-test, a positive Z score difference indicates a decrease in time to run in 2015 compared with 2011

${ }^{\mathrm{b}} \mathrm{S}$ chool decile as determined by the Ministry of Education, scale 1-10: 1 located in lowest, and 10 in highest, socioeconomic area ${ }^{21}$

speed. Previous investigators have reported moderate to strong reliability and validity of the $550 \mathrm{~m}$ (600 yards) run $[17,23]$ and in our hands (unpublished) we have shown that the different day intraindividual variation is $\pm 6 \mathrm{~s} \sim 2.5 \%$.

Data collected in 2011 and 2015 were used for this study as these were the only 2 years where run scores were measured and evaluated in a co-ordinated fashion. As boys and girls grow and develop at different rates at different ages, "measure-for-age" charts are needed to be able to compare measurements of children with a reference population. From the previously developed 2011 run times [24], gender-specific $T_{550}$ charts were published allowing the determination of $\mathrm{T}_{550}$-for-age $\mathrm{Z}$ scores $\left(\mathrm{T}_{550} \mathrm{AZ}\right)$ for a child or group of children. For the 2015 children, as birthdate was not provided, medianage-within-year was used e.g. all 6 year olds were recorded as 6.5 years. Differences in $\mathrm{T}_{550}$ AZ between 2015 and 2011 were determined using independent $\mathrm{t}$ tests. Mean $\mathrm{T}_{550} \mathrm{AZ}$ and $95 \%$ confidence intervals of the mean differences are described and $\mathrm{T}_{550} \mathrm{AZ}$ scores compared systematically by year of measurement, gender, ethnicity and school decile (Table 2).

All continuous data was examined for outliers and tested for normality. Z scores for age and gender adjusted run times are reported as mean and standard 
Table 2 Multiple regression analysis for time to complete in seconds T550 using year of measurement, gender, ethnicity, age and decile

\begin{tabular}{|c|c|c|c|c|c|}
\hline \multirow[t]{2}{*}{ Characteristic } & \multicolumn{3}{|c|}{ Unstandardized Coefficients } & \multicolumn{2}{|c|}{ Standardized Coefficients } \\
\hline & $\begin{array}{l}\text { Beta } \\
\text { sec }\end{array}$ & Std.Error & Difference $(95 \% \mathrm{Cl})$ & Beta & $P$ \\
\hline Constant & 264.1 & 2.3 & $260.1,268.1$ & & $<0.001$ \\
\hline Age & -7.959 & 0.2 & $-8.4,-7.5$ & -0.321 & $<0.001$ \\
\hline Gender & -13.0 & 0.6 & $-14.2,-11.8$ & -0.189 & $<0.001$ \\
\hline Decile & -2.9 & 0.1 & $-3.2,-2.7$ & -0.234 & $<0.001$ \\
\hline Ethnicity & -4.4 & 0.7 & $-5.8,-3.0$ & -0.062 & $<0.001$ \\
\hline Year & 11.3 & 0.6 & $10.1,12.6$ & 0.165 & $<0.001$ \\
\hline
\end{tabular}

Gender Girl 0, Boy 1; Decile linear 1 to 10, Ethnicity 0 Māori, 1 Non-Māori, Year $2011=0,2015=1$

deviation. Differences in $\mathrm{Z}$ scores $\mathrm{T}_{550}$ by year, gender, ethnicity and decile and year of measurement were determined by unpaired $\mathrm{t}$ tests. Magnitude of difference was determined from the $95 \%$ CI of the mean difference. Multiple linear regression analyses to determine associations of age, gender, ethnicity, decile and year of measurement with both $\mathrm{Z}$ scores and time in seconds. All comparisons were two-sided with statistical significance was set at $P<0.05$. Statistical analysis was undertaken using Statistical Package for the Social Sciences (SPSS, v22, IBM).

\section{Results}

In 2015, children ran $550 \mathrm{~m}$ faster than in 2011 ( $\mathrm{Z}$ score 0.11 , Table 1). Specifically, girls ran at a similar speed in 2015 as 2011 but boys were faster than in 2011 ( $\mathrm{Z}$ score comparison $P<0.001$, mean difference 0.18 95\%CI 0.12 , $0.25)$. This unadjusted difference was also seen in all children aged $6(0.19 ; 0.01,0.37, p=0.037), 8$ (0.18; 0.06, $0.30, p=0.0005)$, and $9(0.29 ; 0.28,0.40, p<0.001)$ years.

In the regression analyses adjusting for age, gender, decile, ethnicity and year of measurement, time taken to run $550 \mathrm{~m}$ was $11 \mathrm{~s}$ ( $\mathrm{Z}$ score 0.06) less in 2015 compared with 2011 (Tables 2 and 3). Boys ran 55013 s faster than

Table 3 Multiple regression analysis for prediction of T550 z score using year of measurement, gender, ethnicity, age and decile

\begin{tabular}{|c|c|c|c|c|c|}
\hline \multirow[t]{2}{*}{ Characteristic } & \multicolumn{3}{|c|}{ Unstandardized Coefficients } & \multicolumn{2}{|c|}{$\begin{array}{l}\text { Standardized } \\
\text { Coefficients }\end{array}$} \\
\hline & $B$ & Std.Error & $(95 \% \mathrm{Cl})$ & Beta & $P$ \\
\hline Constant & 0.682 & 0.072 & $0.541,0.824$ & & $<0.001$ \\
\hline Age, y & -0.006 & -0.008 & $-0.021,-0.010$ & -0.007 & 0.482 \\
\hline Gender & -0.075 & -0.022 & $-0.118,-0.032$ & -0.033 & $<0.005$ \\
\hline Decile & -0.102 & -0.004 & $-0.110,-0.093$ & -0.248 & $<0.001$ \\
\hline Ethnicity & -0.151 & -0.025 & $-0.201,-0.102$ & -0.064 & $<0.001$ \\
\hline Year & 0.058 & 0.022 & $-0.101,-0.015$ & -0.026 & $<0.01$ \\
\hline
\end{tabular}

Gender Girl 0, Boy 1; Decile linear 1 to 10, Ethnicity 0 Māori, 1 Non-Mãori, Year $2011=0,2015=1$ girls ( $Z$ score 0.07$)$ and for each 1 year age increase, children were $8 \mathrm{~s}$ faster ( $Z$ score 0.006 ; Table 3$)$. For each $10 \%$ decrease in SES, children were $3 \mathrm{~s}$ slower ( $Z$ score 0.004) and Māori children were $5 \mathrm{~s}$ slower than NonMāori children (Z score 0.15).

\section{Discussion}

The aim of this 2018 analysis was to compare cardiorespiratory fitness $\left(\mathrm{T}_{550}\right)$ levels between 2015 and 2011 of Waikato children participating in Project Energize. Overall, the run scores were faster in 2015 compared to 2011. This is an encouraging statistic and suggests that the PE intervention has maintained the increase in quality physical activity in schools reported previously [5]. A recent meta-analysis of the effect of school-based physical activity interventions aimed at increasing cardiorespiratory fitness found moderate quality evidence supporting their effectiveness [25]. However, this increase was only found in girls, which is in contrast to the findings of this current study. Given that Energizers tailor physical activities to the needs of individual schools may help explain these differences.

In the Waikato region between the periods 2011-2014 and 2014-2017, overweight and obesity prevalence decreased from $36.7 \%(95 \% \mathrm{CI}, 32.7,40.9)$ to $29.2 \%(25.5$, 33.2) [26]. In the same period, there was a small increase for the whole of New Zealand. This suggests that the decrease in body size found in this study may be part of the explanation of the faster run times, supported by the delivery of PE in all Waikato primary schools. Previous research has reported that children whose body fat percentage increases during a physical activity intervention are more likely to also have a decrease in cardiorespiratory fitness [25]. Yet, it can't be ignored that Māori children, schools with higher deprivation and girls, continue to warrant attention. It has been hypothesized that future intervention programs may need to be more aggressive when it comes to positively impacting cardiorespiratory fitness via school-based interventions [25]. Targeting girls [27] and schools that are ethnically 
diverse [28] and have lower socio-economic status [29] may also need to consider alternative approaches.

In addition to the large number of schools who participated, there are several strengths of this study. Firstly, the inclusion of a valid physical fitness measure widens the outcome measures for programme evaluation. Secondly, the anonymous collection of data as part of each school's curriculum is part of the quality control of delivery and reduces participant bias. From a cost perspective, this parsimonious and pragmatic measurement requires minimal equipment and training, and can be repeated with large numbers of children; including those that are geographically remote, in areas of high deprivation and have ethnically diverse populations. Limitations of this study include its cross-sectional design and the inability to identify the contribution of specific components of the PE program to the cardiorespiratory fitness scores recorded. Although our analysis did not take into account the size of the school, clustering effects or years of attendance of child at the school, the large number of children tested and inclusion of more than $80 \%$ of the schools in the region in 2011 and 2015 meant that there was good representation of the region.

Although program adherence data was not collected between 2011 and 2015 for each individual school, adherence was reported to the funder by all Energizers in the form of quarterly reports for the region. This report described overall, the number of interactions and activities undertaken.

\section{Conclusion}

The findings from this study support the continuation of the delivery of Project Energize in the Waikato region of New Zealand, as cardiorespiratory fitness scores in 2015, compared to 2011, were improved, particularly for lower SES schools and for Māori children. Ethnically diverse populations, schools with higher deprivation and girls, continue to warrant further attention to help achieve equity.

\section{Abbreviations}

$\mathrm{T}_{550}$ AZ: T550-for-age Z scores; SES: School socioeconomic status; PE: Project Energize; BMI: Body mass index; AUTEC: Auckland University of Technology ethics committee

\section{Acknowledgements \\ The authors wish to thank Stephanie McLennan and Kasha Latimer, Sport Waikato, and the many Energizers involved in the measurement of the children's run times.}

\section{Authors' contributions}

CC wrote the first draft and supported data analysis, VC and ER undertook statistical analysis, TC substantively critiqued and revised the work, ER was responsible for conception, acquisition and interpretation of the data and all have approved the submitted version and are personally accountable.
Funding

None.

Availability of data and materials

The dataset supporting the conclusions of this article are available by contacting Professor Elaine Rush directly.

\section{Ethics approval and consent to participate}

For the 2011 measures the Northern Y Regional Ethics Committee (NTY/10/ 04/41) provided ethical approval in 2010 and caregivers and children provided written and signed informed consent. There were no inclusion/ exclusion criteria for participation and all children were invited to participate. Anonymised data supplied in 2015 was an audit of the usual evaluation of PE and the Auckland University of Technology ethics committee (AUTEC) attested that the analysis met ethical criteria.

\section{Consent for publication}

Not applicable.

\section{Competing interests}

The authors report no conflict of interest.

\section{Author details}

${ }^{1}$ School of Sport and Recreation, Auckland University of Technology, Auckland, New Zealand. 'Department of Sport, Leisure \& Childhood Studies, Cork Institute of Technology, Cork, Ireland.

Received: 6 May 2020 Accepted: 20 August 2020

Published online: 17 September 2020

\section{References}

1. Ministry of Health. New Zealand Health Survey 2018/19, [https:// minhealthnz.shinyapps.io/nz-health-survey-2017-18-annual-data-explorer] Accessed 19 Nov 2019.

2. Nishtar S, Gluckman P, Armstrong T. Ending childhood obesity: a time for action. Lancet. 2016:387(10021):825-7.

3. Rush E, Cairncross C, Williams MH, Tseng M, Coppinger T, McLennan S, Latimer K. Project energize: intervention development and 10 years of progress in preventing childhood obesity. BMC Res Notes. 2016;9:44

4. Rush E, Reed P, McLennan S, Coppinger T, Simmons D, Graham D. A school-based obesity control programme: project energize. Two-year outcomes. Br J Nutr. 2012;107(4):581-7.

5. Mitchell B, McLennan S, Latimer K, Graham D, Gilmore J, Rush E. Improvement of fundamental movement skills through support and mentorship of class room teachers. Obes Res Clin Pract. 2013:7(3):e230-4

6. Graham D, Appleton S, Rush E, McLennan S, Reed P, Simmons D. Increasing activity and improving nutrition through a schools-based programme: project energize. 1. Design, programme, randomisation and evaluation methodology. Public Health Nutr. 2008;11(10):1076-84.

7. Deaton A, Cartwright N. Understanding and misunderstanding randomized controlled trials. Soc Sci Med. 2018:210:2-21.

8. Kessler R, Glasgow RE. A proposal to speed translation of healthcare research into practice: dramatic change is needed. Am J Prev Med. 2011; 40(6):637-44.

9. Brennan LK, Brownson RC, Orleans CT. Childhood obesity policy research and practice: evidence for policy and environmental strategies. Am J Prev Med. 2014;46(1):e1-16.

10. Murray C, Chambers R. Keeping score: fostering accountability for children's lives. Lancet. 2015;386(9988):3-5.

11. Psaltopoulou T, Tzanninis S, Ntanasis-Stathopoulos I, Panotopoulos G, Kostopoulou M, Tzanninis IG, Tsagianni A, Sergentanis TN. Prevention and treatment of childhood and adolescent obesity: a systematic review of meta-analyses. World J Pediatr. 2019;15(4):350-81.

12. Ekelund U, Anderssen S, Froberg K, Sardinha LB, Andersen LB, Brage $S$, Group EYHS. Independent associations of physical activity and cardiorespiratory fitness with metabolic risk factors in children: the European youth heart study. Diabetologia. 2007:50(9):1832-40.

13. Varni JW, Burwinkle TM, Lane MM. Health-related quality of life measurement in pediatric clinical practice: an appraisal and precept for future research and application. Health Qual Life Outcomes. 2005;3:34. 
14. Benson AC, Torode ME, Singh MA. Muscular strength and cardiorespiratory fitness is associated with higher insulin sensitivity in children and adolescents. Int J Pediatr Obes. 2006;1(4):222-31.

15. Oja L, Jurimae T. Physical activity, motor ability, and school readiness of 6yr.-old children. Percept Mot Skills. 2002;95(2):407-15.

16. Hanson S, Jones A. Missed opportunities in the evaluation of public health interventions: a case study of physical activity programmes. BMC Public Health. 2017;17(1):674.

17. Safrit MJ. The validity and reliability of fitness tests for children: a review. Pediatr Exerc Sci. 1990;2(1):9-28.

18. Hamlin MJ, Ross JJ. Barriers to physical activity in young new Zealanders. Youth Studies Australia. 2005;24(1):31.

19. Rush E, McLennan S, Obolonkin V, Vandal AC, Hamlin M, Simmons $D$, Graham D. Project energize: whole-region primary school nutrition and physical activity programme; evaluation of body size and fitness 5 years after the randomised controlled trial. Br J Nutr. 2014;111(2):363-71.

20. Kendziora K, Dymnicki A, Faria A-M, Windham A, Osher D. Conducting prevention research and evaluation in schools. In: Prevention Science in School Settings. New York: Springer; 2015. p. 227-46.

21. Ministry of Education. School deciles [https://www.education.govt.nz/ school/funding-and-financials/resourcing/operational-funding/school-decileratings// Accessed 6 Jan 2020.

22. Dawson K, Hamlin M, Ross J, Duffy D. Trends in the health-related physical fitness of 10-14 year old New Zealand children. N Z Phys Educ. 2001;34(1):26.

23. Hamlin MJ, Fraser M, Lizamore CA, Draper N, Shearman JP, Kimber NE. Measurement of cardiorespiratory fitness in children from two commonly used field tests after accounting for body fatness and maturity. J Hum Kinet. 2014;40:83-92

24. Rush E, Obolonkin V. Waikato 2011 centile charts for assessment of time to run 550m [Microsoft Excel workbook] [https://openrepository.aut.ac.nz/ handle/10292/8235] Accessed 6 Jan 2020.

25. Pozuelo-Carrascosa DP, García-Hermoso A, Álvarez-Bueno C, Sánchez-López M, Martinez-Vizcaino V. Effectiveness of school-based physical activity programmes on cardiorespiratory fitness in children: a meta-analysis of randomised controlled trials. Br J Sports Med. 2018:52(19):1234-40.

26. Ministry of Health. NZ health survey compare regions [https://minhealthnz. shinyapps.io/nz-health-survey-2014-17-regional-update/_w_9b26d94b/ \#!/compare-regions] Accessed 6 Jan 2020.

27. Morgan PJ, Young MD, Barnes AT, Eather N, Pollock ER, Lubans DR. Engaging fathers to increase physical activity in girls: the "dads and daughters exercising and empowered"(DADEE) randomized controlled trial. Ann Behav Med. 2019;53(1):39-52.

28. Maynard M, Baker G, Harding S. Exploring childhood obesity prevention among diverse ethnic groups in schools and places of worship: recruitment, acceptability and feasibility of data collection and intervention components. Prev Med Rep. 2017;6:130-6.

29. Hankonen N, Heino MT, Kujala E, Hynynen S-T, Absetz P, Araújo-Soares V, Borodulin $\mathrm{K}$, Haukkala A. What explains the socioeconomic status gap in activity? Educational differences in determinants of physical activity and screentime. BMC Public Health. 2017;17(1):144

\section{Publisher's Note}

Springer Nature remains neutral with regard to jurisdictional claims in published maps and institutional affiliations.

Ready to submit your research? Choose BMC and benefit from:
- fast, convenient online submission
- thorough peer review by experienced researchers in your field
- rapid publication on acceptance
- support for research data, including large and complex data types
- gold Open Access which fosters wider collaboration and increased citations
- maximum visibility for your research: over 100M website views per year
At BMC, research is always in progress.
Learn more biomedcentral.com/submissions

